\title{
The effect of organizational citizenship behavior on organizational commitment
}

\author{
Kaveh Hasani • Saeed Sadeghi Boroujerdi • \\ Saman Sheikhesmaeili
}

Published online: 31 October 2013

(C) International Network of Business and Management 2013

\begin{abstract}
The purpose of this study was to survey the relationship between organizational citizenship behavior and organizational commitment. Research method is descriptive-correlative and it was applied based on the related purpose. Statistical population included all staff of Physical education departments in Iran, whose number was 1,225 at the time of the study. Also, statistical sample including 293 subjects was selected using Morgan table. The independent variables of research included dimensions of organizational citizenship behavior and the dependent variables included dimensions of organizational commitment. The statistical analyses of the study results show that all alternative hypotheses were supported and the null hypotheses were rejected.
\end{abstract}

Keywords Organizational citizenship behavior · Organizational commitment · Affective commitment · Continuance commitment · Normative commitment

\footnotetext{
K. Hasani $(\bowtie)$

Department of Management, Young Researchers and Elite Clubs, Sanandaj Branch, Islamic Azad University of Sanandaj, Sanandaj, Iran

e-mail: kaveh.hhh@Gmail.com
}

S. S. Boroujerdi

Department of Physical Education, University of Kurdistan, Sanandaj, Iran e-mail: sboroujerdi@uok.ac.ir

S. Sheikhesmaeili

Department of Human Science, Young Researchers and Elite Clubs, Sanandaj Branch, Islamic Azad University, Sanandaj, Iran

e-mail: cikole1332@gmail.com 


\section{Introduction}

In today's competitive world, organizations are constantly looking for new methods to maximize their personnel's efficiency and endeavor. Different conditions of organizations at present, increasing rate of competitions and their affection in this condition lead organizations to have new generation of personnel, a generation which is called soldiers of organization. Definitely, these personnel distinguish between affective and non-affective organizations (Podsakoff et al. 2000). Organizational citizenship behavior (OCB) was first presented to science world by Batman and Organ (1983). Organ thought OCB as personal and arbitrary behaviors which were not correctly defined by the formal remuneration system of organization and generally increased organization's productivity. Arbitrary means that this behavior is not among the occupational duties or role behaviors and it is not among the employees' recruitment commitment and it is not compulsory for employees to do it (Podsakoff et al. 2000). Success of organizations depends on performance of the employees who act beyond their duties and roles; these efforts that are beyond roles and expectations of organization and management literature are called practical or OCB (DiPaola and Tschannen-Moran 2001).

Organizational citizenship behavior is defined as some phrases such as good soldier, arbitrary behavior, volunteer behavior, and practical behavior; it creates a new phrase in organizational science especially in organizational behavior that has a remarkable role in organizational affection (Garg and Rastogi 2006). OCB has a close relationship with organizational commitment. In two recent decades, organizational commitment was regarded by researchers as a dominant attitude and was a subject for ultra-analyses; modern attitude toward organizational commitment is a multi-dimensional attitude, so other researchers' works focus on different kinds of commitments that can be regarded to specify behavior in work environment (Dickinson 2009). Commitment shows the most meaningful form among the organizational duties and maximum constancy in organization and it shows powerful relationship with organization's citizenship behaviors (Cohen 2006). Luthans (2006) stated that commitment includes 1: to stay for a long time. 2 : to accept organizational norms and values. and 3: widespread participation to reach growth and development (Luthans 2006). Organizational commitment is one of the important factors that caused to strengthen the OCB (Lepine et al. 2002). Organizational commitment is positively associated with OCB (O`Reilly and Chatman 1986). Organizations especially in undeveloped or developing countries should provide opportunity for their managers and employees to use their experiences, abilities as well as their potential to improve organizational goals and this cannot come true until there is a suitable opportunity for OCB and personnel organizational commitment. Iran Physical education departments as a main reliable sport organization of this country whose function in all sport aspects from cultural and general to championship and professional is to increase employees' productivity; and based on managers' decisions in this organization, it can be concluded that they wanted to improve employees' commitment to organization such that they improve employees' performance level. In other words, keeping current human resources especially faithful human potential with 
citizenship behaviors and Manpower commitment is regarded as a one of the main goals of this organization that this study regarded. Accordingly, researchers try to evaluate citizenship behavior variables obtained from Graham's (1991) citizenship behavior on the rate of humans' organizational commitment that are obtained from Meyer and Allen's (1990) model. Review of the research literature in the world suggests that major modeling studies have been conducted in the field of OCB in the 80 and 90 s, for example, Batman and Organ (1983), Organ (1988), Organ (1990), Podsakoff et al. (1990), Graham (1991), Podsakoff and MacKenzie (1994), Van Dyne et al. (1994), Moorman and Blakely (1995), Van Scotter and Motowidlo (1996), Farh et al. (1997), Van Dyne and Ang (1998), etc., did modeling and conceptualization well in OCB. The "organizational commitment" variable is also studied under these conditions. For example, Mowday et al. (1982), Mathieu and Zajac (1990), Meyer and Allen (1990), Meyer (1997), etc., conducted important studies. Consequently, OCB models of Graham (1991) and organizational commitment framework of Meyer and Allen (1990) among them were suitable for testing. The model of commitment has been used by many researchers to predict important outcomes of employee including turnover and citizenship behaviors, job performance, absenteeism, and tardiness (Meyer et al. 2002). In these cases, researcher followed employees' citizenship behavior and organizational commitment for finding scientific answers for the following questions according to the ruling Bureaucratic and cold relations in these organizations: Are there significant relationships between OCB and staff's organizational commitment? Are there significant relationships between OCB and affective commitment of staff? Are there significant relationships between OCB and continuance commitment of staff? Are there significant relationships between OCB and normative commitment of staff?

\section{Organizational citizenship behavior}

Today, one key issue in the study of organizational behavior and the related disciplines is motivation of the employees to work more. In recent decades, OCB is a key structure in psychology and management that has strong interaction with other variables, and is used in various topics (Batman and Organ 1983; Bergeron 2007; Bolino et al. 2002; Lepine et al. 2002; Niehoff and Moorman 1993; Organ 1988; Organ and Ryan 1995; Podsakoff et al. 2000; Tang et al. 2008). Research on OCB defined as the behavior which is discretionary and informal work environment to enhance profitability of the entire organization has been recommended (Chompookum and Derr 2004; Kidwell et al. 1997; Organ 1988; Podsakoff et al. 2000; Van Scotter 2000). Additionally, OCB is possible to incorporate the culture of the organization, because organizational culture directly and indirectly affect employees' psychological characteristics (Stamper and Van Dyne 2001), and this increased interest in the management literature and psychology in recent years. Organ regards OCB as personal behaviors that are arbitrary and are not directly and clearly stated by formal testimonial system of organization which generally increases organization's efficiency. Arbitrary means that behavior is not among the job duties or role behaviors and it is not among employees' recruitment commitment, it is elective, 
and if it is not performed there will be no punishment for it (Podsakoff et al. 2000). These behaviors caused some actions that are helpful and gainful for organizations by keeping psychological and social texture support and they are not done at requests (levy 2004). OCBs are practical, helpful, and social behaviors (Alotaibi 2001). Graham (1991) presented a model of OCB and identified three components: (1) Organizational obedience; (2) Organizational loyalty; and (3) Organizational partnerships.

Organizational obedience This term describes behaviors that identified the need and desirability of reasonable structure and discipline which are accepted. Indicators of corporate compliance are behaviors such as respect for the rules of submission, complete tasks and responsibilities regarding organization's resources.

Organizational loyalty loyalty to the organization is different from loyalty to self, to other individuals and organizational units and it states expression level of dedication of staff to protect and defend values of organization.

Organizational partnerships This term is accompanied by participation of employee in corporate governance to which we can point to attend meetings to share ideas with others and to be aware of the current issues (Bienstock et al. 2003).

Organizational commitment

More than half a century, organizational commitment in the workplace attracted attention of the scientific community. Many definitions of organizational commitment have been proposed by various researchers, but it is well accepted that commitment reflects feelings of dependency, identity, and loyalty in order to achieve that goal (Morrow 1983).

Commitment is an important issue in management literature. This idea is one of the fundamental values on which the organization relies and staffs are assessed based on commitment criteria (Cohen 1993). Organizational commitment is one of the hidden but affective factors in staffs' occupational behaviors (Bienstock et al. 2003) and it is a kind of attitude and affective condition that shows rate of tendency and need as well as obligation to keep on job in organization. Organizational commitment is described as an attitude or orientation to organization which shows person's identity to organization (Gautam et al. 2004) and the feeling of belonging to the organization (Markovits et al. 2008) and the tendency of people to put their energy and loyalty (Kim and leong 2005) to social system (Meyer et al. 2002) on which basis it finds their identity in organization. Organizational commitment can be defined as a psychological state that characterizes an employee's relationship with the organization and reduces the likelihood that he/she will leave it (Allen and Meyer 2000). Also, Allen and Meyer (2000) had stated that several variables of work attitude were studied by organizational psychologists and in these studies, only 
job satisfaction among work attitude variables has been more considered by research than organizational commitment. Organizational commitment refers to employees' belief in organization's goals and values, a willingness to maintain membership in the organization, and loyalty to the organization (Mowday et al. 1983; Hackett et al. 2001). Also, organizational commitment can serve as a strong relationship between identity of the people and their participation in organization (Mowday et al. 1979). Meyer and Allen (1990) presented a model of organizational commitment and identified three components: (1) Affective commitment; (2) Continuance commitment; and (3) Normative commitment.

Affective commitment Includes staffs' emotional attachment to identity appointment with organization and to engagement in organizational activities.

Continuance commitment Includes a willingness to stay in the organization because of organization turnover costs or rewards of staying in the organization.

Normative commitment Includes personal feeling of people to stay in the organization.

Organizational citizenship behavior and organizational commitment

In this study, the researcher examines the background of the study and reviews the work of other researchers in this field. Meyer and Allen (1990) developed a threecomponent model, consisting of affective commitment, continuance commitment, and normative commitment. They defined affective commitment as being based on one's values, normative commitment as being based on obligation, and continuance commitment as being based on calculation of costs and benefits. They argue that these components are differentially linked to variables as antecedents and consequents (Meyer and Allen 1991).

Ensher et al. (2001), in a study entitled, "Effects of perceived discrimination on job satisfaction, organizational commitment, OCB, and grievances" concluded that all three types of perceived discrimination had an effect on organizational commitment, job satisfaction, and OCB. Contrary to the predictions, however, there was no relationship with grievances (Ensher et al. 2001).

Another study was conducted in Nepal by Gautam et al. (2005) on OCB and organizational commitment with a sample size of 450 people in five organizations. The results showed that there was a significant positive relationship between organizational commitment and OCB (Gautam et al. 2005).

Haigh and Pfau (2006), in a study entitled "Bolstering organizational identity, commitment, and citizenship behaviors through the process of inoculation" concluded that organizational identity, organizational commitment, and certain OCBs could be strengthened through internal communication (Haigh and Pfau 2006).

Lavelle et al. (2009), in their study entitled "Commitment, procedural fairness, and organizational citizenship behavior: a multifocal analysis" concluded that: (1) the positive relationship between commitment and OCB, and (2) the mediating 
effect of commitment on the positive relationship between procedural fairness and OCB were particularly likely to emerge when the constructs referred to the same target. Support of these target similarity effects was found among layoff survivors (Study 1) and student project teams (Study 2), (Lavelle et al. 2009).

$\mathrm{Ng}$ and Feldman (2011) in a study entitled "Affective organizational commitment and citizenship behavior: Linear and nonlinear moderating effects of organizational tenure," concluded that organizational tenure moderated the relation nonlinearly. Before 10 years of tenure, the strength of the commitment-OCB relation increased as organizational tenure increased; after that point, the strength of the commitment-OCB relation decreased as organizational tenure increased. In short, the moderating effect of tenure follows a curvilinear pattern ( $\mathrm{Ng}$ and Feldman 2011).

Salehi and Gholtash (2011) in Iran performed a study entitled "The relationship between job satisfaction, job burnout and organizational commitment and the organizational citizenship behavior among members of faculty in the Islamic Azad University - first district branches for providing the appropriate model." In this study, for collecting data five questionnaires of OCB (Graham 1991), job satisfaction, job burnout, and organizational commitment (Meyer and Allen 1991) were applied; results showed that variables of job satisfaction and organizational commitment had a positive effect on the OCB while job burnout had a negative effect on it. Job satisfaction has a negative effect on job burnout (Salehi and Gholtash 2011).

Zeinabadi and Salehi (2011) in a research entitled "Role of procedural justice, trust, job satisfaction, and organizational commitment in Organizational Citizenship Behavior (OCB) of teachers: Proposing a modified social exchange model" in Iran showed a good fit of the proposed model of this research. According to this model, procedural justice has two lines to promote OCB of teacher: first, through influencing teacher trust and second, influencing OCB of teacher through job satisfaction and organizational commitment (Zeinabadi and Salehi 2011).

Morin et al. (2011) in a study entitled "Affective commitment and citizenship behaviors across multiple foci" concluded that commitments to coworkers, customers, and supervisors displayed positive relationships with OCBs directed at parallel foci. In addition, commitment to the global organization partially and negatively mediated the relationship between commitments to coworkers and customers and parallel dimensions of OCBs. Results also revealed cross-foci relationships between local commitments and OCBs. Finally, no commitment target was significantly associated with organization-directed OCBs but the latter was positively related to local OCBs (Morin et al. 2011).

Mirabizadeh and Gheitasi (2012) in Iran at a study entitled "Examining the organizational citizenship behavior as the outcome of organizational commitment: Case study of universities in Ilam" concluded that educational opportunities, worklife policy, and empowerment activities had strong positive relationship with organizational commitment; and organizational commitment also influenced OCB accordingly (Mirabizadeh and Gheitasi 2012).

Chen and Kao (2012) in a study entitled "Work Values and Service-Oriented Organizational Citizenship Behaviors: The Mediation of Psychological Contract 
and Professional Commitment: A Case of Students in Taiwan Police College" concluded that psychological contract and professional commitment had positive effects on service-oriented OCBs. Besides, work values are found to have a positive effect on service-oriented OCBs through the mediation of psychological contract and professional commitment (Chen and Kao 2012). Results of the previous researches show that commitment is the predictive of OCB because it significantly impacts on OCB (Liu 2009; Islam et al. 2012).

\section{Research's proposed model}

Importantly, the research proposed model was based on the theoretical relationships between numbers of factors which have been predicted in the research. In this research, OCB with dimensions of Organizational obedience, Organizational loyalty, Organizational partnerships, and organizational commitment with dimensions of Affective commitment, Continuance commitment, and Normative commitment were used according to the research title, based on theoretical basics and by reviewing the research literature. This proposed model represents the relationship between OCB model proposed by Graham (1991) and organizational commitment model proposed by Meyer and Allen (1991). According to the type of organizational culture, demographic characteristics and background of studies in Iran, this model was predicted to be used from these two models. So, the general structures of Fig. (1) regarding the relationship between measure and review are as follows:

According to Fig. (1), the research proposed model was derived from OCB model proposed by Graham (1991) and organizational commitment model derived from Meyer and Allen (1991).

According to Fig. (2), Research measurement model shows the paths of research hypotheses and provides a basis for the analytical tests. Therefore, regarding the goal and proposed model of the study, the main hypothesis of the research and subhypotheses are as follows:

Main hypothesis

There is significant relationship between OCB and staff's organizational commitment.

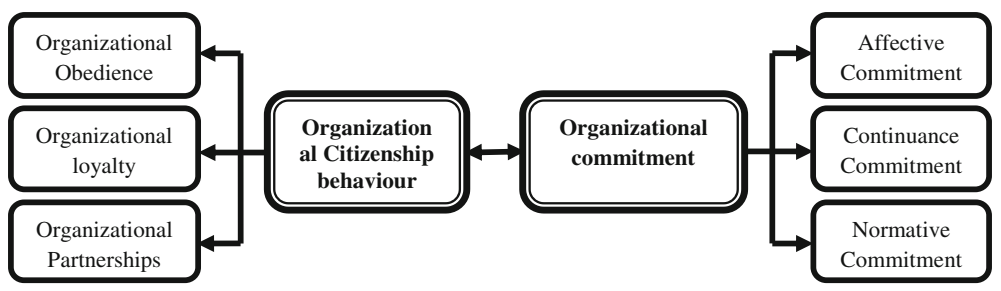

Fig. 1 The proposed model research 


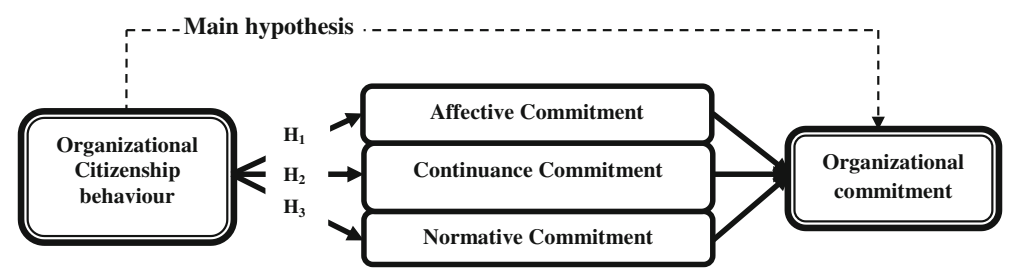

Fig. 2 Research measurement model (RMM)

Sub-hypothesis

[1] There is a significant relationship between OCB and staff's affective commitment.

[2] There is a significant relationship between OCB and staff's continuance commitment.

[3] There is a significant relationship between OCB and staff's normative commitment.

\section{Research methodology}

The research method

The purpose of this study was to survey the relationship between OCB and organizational commitment in Physical education departments. Research method was of descriptive-correlative type and was an applied method in terms of goal. Statistical population of research included all staffs of physical education offices in the provinces of Kurdistan, Kermanshah, West Azerbaijan, and Hamadan whose number was 1,225 at the time of research. Statistical sample using Krejcie and Morgan (1970) table was selected to be 293 individuals and roles of physical education offices in provinces of Kurdistan, Kermanshah, West Azerbaijan, and Hamadan. This researcher has used random sampling method for selection of sample.

\section{Research variables}

Independent variables consisted of citizenship behavior dimensions that include organizational obedience, organizational loyalty, organizational partnerships, and dependent variables also included organizational commitment dimensions including affective commitment, continuance commitment, and normative commitment.

Measurement instruments

To measure the research variables, two researcher-made questionnaires were used which included: (A) citizenship behavior questionnaire which was adapted from Graham's standard questionnaire (1991) which included 30 questions and (B) organizational commitment questionnaire adapted from Meyer and Allen's (1990) 
standard questionnaire which included 21 questions. Both of these questionnaires had five-choice scale (very low, low, medium, high, and very high).

Validity and reliability of questionnaires

Reliability of the questionnaire was calculated as 0.92 and 0.89 for two variables and verified with Cronbach's alpha method. Also, validity of the research questions including face validity and truth of the questions was confirmed by some experts and specialists while standardization and normalization of the questionnaire in other studies confirmed its validity. To check the adequacy of the sample, Kaiser-MeyerOlkin Test (KMO) was used. In this study, KMO sampling adequacy for dimensions of citizenship behavior was 0.912 and for organizational commitment dimensions, it was 0.907 . In order to check whether the data were able to become agents, Bartlett's Test of Sphericity was used and the obtained value was 2.86 which was significant at the level of $(0.01>P)$. For factor analysis, principal components method and Varimax orthogonal rotation were also used. For factor analysis of the citizenship behavior dimensions, 34 factors were used in questionnaire in which percent of the explained total variance in the first factor (Organizational obedience) was 51.01, it was 18.8 for the second factor (Organizational loyalty), it was 15.2 for the third factor (Organizational partnerships), and it was equal to 85.06 for the period of the explained total variance. For factor analysis of the organizational commitment, 24 factors were explained in questionnaire in which it was equal to 8.765 for the first factor (Affective commitment), 7.871 for the second factor (Continuance commitment), and 3.856 for the third factor (Normative commitment) and percent of the explained total variance is equal to 86.5 .

Statistical analysis methods

In this research, descriptive and inferential statistics was used. Descriptive statistics was used for describing data of research and Kolmogorov-Smirnov's (K-S) test was used in inferential statistics and to survey the hypotheses, The Pearson correlation test was used. In addition, confirmatory path analysis based on structural equation model (SEM) was used to evaluate study's model. Significance level in this research was considered as 0.05 and SPSS and Lisrel softwares were used for analyzing data.

\section{Results}

Sample descriptive data

Respondents' descriptive information on the study, in terms of gender, age, education, and work experience are explained in Table 1.

Table 1 shows that most of the respondents to the questionnaire were male employees based on the "Gender." Based on the "Age" of the respondents, results show that most respondents were between 30 and 40 years and between 40 and 50 years; and based on the "Education" of the respondents, results show that most respondents held bachelor's and master's degrees and it can be inferred that subjects 
Table 1 Descriptive statistics

\begin{tabular}{|c|c|c|c|c|c|c|c|}
\hline \multicolumn{2}{|l|}{ Gender } & \multicolumn{2}{|l|}{ Age } & \multicolumn{2}{|l|}{ Education } & \multicolumn{2}{|c|}{ Work experience } \\
\hline Level & Percent & Level & Percent & Level & Percent & Level & Percent \\
\hline \multirow[t]{3}{*}{ Male } & 85.5 & Under 30 years & 13.7 & Diploma & 0 & Under 5 years & 7.7 \\
\hline & & $30-40$ & 39.3 & Up diploma & 17.47 & $5-10$ & 12.8 \\
\hline & & $40-50$ & 35.0 & Associate of arts & 47.25 & $10-15$ & 37.6 \\
\hline \multirow[t]{2}{*}{ Female } & 14.5 & Up 50 years & 12.0 & MA & 25.90 & $15-20$ & 19.7 \\
\hline & & & & $\mathrm{PhD}$ & 12.38 & Up 20 years & 22.2 \\
\hline Total & 100 & & 100 & & 100 & & 100 \\
\hline
\end{tabular}

Table 2 K-S test regarding organizational citizenship behavior and its dimensions

Table $3 \mathrm{~K}-\mathrm{S}$ test regarding the organizational commitment and its dimensions

\begin{tabular}{lll}
\hline Variables & Sig & Results \\
\hline Organizational obedience & 0.257 & Normal \\
Organizational loyalty & 0.327 & Normal \\
Organizational partnerships & 0.481 & Normal \\
Organizational citizenship behavior & 0.355 & Normal \\
\hline
\end{tabular}

\begin{tabular}{lll}
\hline Variables & Sig & Results \\
\hline Affective commitment & 0.454 & Normal \\
Continuance commitment & 0.763 & Normal \\
Normative commitment & 0.635 & Normal \\
Organizational commitment & 0.617 & Normal \\
\hline
\end{tabular}

with more knowledge filled out the questionnaires. Also, based on the "Work Experience" of the respondents, results show that most respondents were between 10 and 15 years and over 20 years.

Results obtained from hypotheses test

\section{Data normality test}

To study normality hypothesis of $\mathrm{OCB}$ and organizational commitment, $\mathrm{K}-\mathrm{S}$ test was used and the results are shown in Tables 2 and 3.

As observed above, significance level of aspects of OCB and organizational commitment is larger than 0.05 considering Tables 2 and 3; as a result, normality of data is confirmed.

\section{The analytical results}

\section{Sub-hypotheses test}

Based on sub-hypotheses of the research, there is a significant relationship between employees' OCB and organizational commitment (affective commitment, 
Table 4 The correlation between the organizational citizenship behavior and dimensions of organizational commitment

\begin{tabular}{lllll}
\hline Dependent variable & \multicolumn{2}{l}{ Independent variable } & \\
\cline { 2 - 5 } & \multicolumn{2}{l}{ Organizational citizenship behavior } & & \\
\cline { 2 - 5 } $\begin{array}{l}\text { Organizational } \\
\text { commitment }\end{array}$ & $\begin{array}{l}\text { Intensity } \\
\text { correlated }\end{array}$ & $\begin{array}{l}\text { Significant } \\
\text { level }(\mathrm{Sig})\end{array}$ & Test result & $\begin{array}{l}\text { Hypothesis } \\
\text { result }\end{array}$ \\
\hline $\begin{array}{l}\text { Affective commitment } \\
\text { Continuance commitment }\end{array}$ & 0.85 & $<0.001$ & $\mathrm{H}_{0}$ rejected & Confirmed \\
Normative commitment & 0.83 & $<0.001$ & $\mathrm{H}_{0}$ rejected & Confirmed \\
\hline
\end{tabular}

Table 5 The correlation between dimensions of organizational citizenship behaviors and organizational commitment

\begin{tabular}{lllll}
\hline Independent variable & \multicolumn{2}{l}{ Dependent variable } & \\
\cline { 2 - 5 } & \multicolumn{2}{l}{ Organizational commitment } & & \\
\cline { 2 - 5 } $\begin{array}{l}\text { Organizational citizenship } \\
\text { behaviors }\end{array}$ & $\begin{array}{l}\text { Intensity } \\
\text { correlated }\end{array}$ & $\begin{array}{l}\text { Significant } \\
\text { level }(\mathrm{Sig})\end{array}$ & $\begin{array}{l}\text { Test } \\
\text { result }\end{array}$ & $\begin{array}{l}\text { Hypothesis } \\
\text { result }\end{array}$ \\
\hline Organizational obedience & 0.87 & $<0.001$ & $\mathrm{H}_{0}$ rejected & Confirmed \\
Organizational loyalty & 0.78 & $<0.001$ & $\mathrm{H}_{0}$ rejected & Confirmed \\
Organizational partnerships & 0.83 & $<0.001$ & $\mathrm{H}_{0}$ rejected & Confirmed \\
Organizational citizenship behaviors & 0.85 & $<0.001$ & $\mathrm{H}_{0}$ rejected & Confirmed \\
\hline
\end{tabular}

continuance commitment, and normative commitment). Results of Pearson correlation test for studying relationship between employees' OCB and organizational commitment are shown in Table 4.

The data obtained in Table 4 for all 3 indices show that the obtained significance level $(\operatorname{Sig}<0.001)$ is below the research alpha $(\alpha=0.05)$; therefore, there are significant relationships among OCB and affective commitment at the level of (0.85), continuance commitment at the level of (0.83), and normative commitment at the level of (0.78), and it can be also stated that intensity of correlation between the OCB and dimensions of organizational commitment is high at the levels of 0.85 , 0.83 , and 0.78 , and type of the correlation between the OCB and dimensions of organizational commitment is direct (positive) and the significance level is calculated ( $\operatorname{Sig}<0.001)$ which is less than $(\alpha=0.05)$ and indicates the significance of the relationship between the OCB and dimensions of organizational commitment. So, sub-hypotheses of the research are confirmed.

Major hypothesis test

\section{Main hypothesis test}

There is a significant relationship between OCB and organizational commitment. Test results of correlation between OCB and organizational commitment are shown in Table 5. 
Table 6 Confirmatory path analysis results based on structural equation model

\begin{tabular}{llllll}
\hline Variable & Sign in model & Standard index & Standard deviation & $t$ & $P$ value \\
\hline Organizational obedience & O.O & 1.00 & 0.07 & 3.83 & $<.001$ \\
Organizational loyalty & O.L & 0.97 & 0.08 & 3.54 & $<.001$ \\
Organizational partnerships & O.P & 0.95 & 0.01 & 3.73 & $<.001$ \\
Affective commitment & A.C & 0.87 & 0.05 & 5.34 & $<.001$ \\
Continuance commitment & C.C & 0.95 & 0.01 & 3.73 & $<.001$ \\
Normative commitment & N.C & 0.90 & 0.09 & 2.9 & $<.001$ \\
\hline
\end{tabular}

The obtained results indicate Pearson's significant test at significance level of $($ Sig $<0.001)$ and there is a relationship between variables of OCB and organizational commitment at the Pearson product moment correlation (0.85). Therefore, it can be stated that intensity of correlation between these two variables is high at the level of 0.85 , type of the correlation between the two variables is direct (positive) and the significance level is calculated (Sig $<0.001)$ which is less than $(\alpha=0.05)$ and indicates the significance of the relationship between the two variables. Therefore, the hypothesis is supported; Table 6.

\section{Confirmatory path analysis results based on structural equation model}

In SEM, $t$ index is used for significance of testing the considered indexes in the model. So, the indexes which have values of larger than (2) are statistically significant. According to the results reported in Table 7 and $t$ values for each of the standard indexes, we can state that the results of this Table are valid for all indexes because all reported $t$ values are higher than the value of (2) in contrast with the standard indexes.

To prepare the measurement model, the effects of variables on each other are unclear but this issue is considered in structural equation modeling or path analysis. Since in this study, only a structural causal relationship of organizational commitment was considered as the dependent variable (OC) and structures of OCB were considered as independent variable (OCB), there is only one value of gamma which is significant considering value of $(t)$. The high value of path coefficient (0.92) in Table 7 shows the influence of OCB on organizational commitment. As the fitness indexes of Table 8 show, the data for this study have a good fitness with the factor structure, the theoretical foundation of organizational commitment, and OCB. Therefore, the data collected in this study were fitted well

Table 7 Confirmatory path analysis results based on structural equation model

\begin{tabular}{llr}
\hline $\begin{array}{l}\text { Gamma value (The effects of organizational citizenship } \\
\text { behavior on organizational commitment) }\end{array}$ & Standard deviation & $t$ \\
\hline 0.92 & 0.14 & 3.15 \\
\hline
\end{tabular}


Table 8 Fitness indexes of LISREL general model of the research conceptual framework

\begin{tabular}{llc}
\hline Index & Index & Reported Value \\
\hline Chi square & $\chi^{2}$ & 14.28 \\
Chi square divided by degree of freedom & $\chi^{2} / \mathrm{df}$ & 8 \\
Root mean square residual & RMR & 0.0043 \\
Goodness of fitness index & GFI & 0.92 \\
Adjusted goodness of fit index & AGFI & 0.91 \\
Nor med fit index & NFI & 0.91 \\
Non-nor med fit index & NNFI & 0.95 \\
Increasing the fitness index & IFI & 0.94 \\
Comparative fit index & CFI & 0.95 \\
Root mean square error of approximation & RMSEA & 0.007 \\
\hline
\end{tabular}

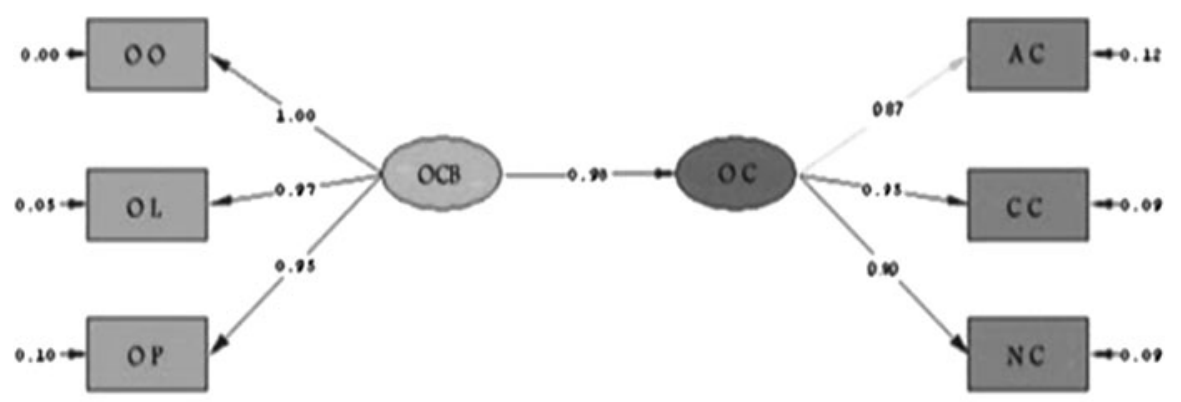

Ch1-square $=14.28, d f=8, p-v a l u e=0.00430$, pMsed $=0.007$

Fig. 3 LISREL general model designed to explain the theoretical framework of the research

with this model. In Fig. 3, the final model developed using LISREL software is presented which is the final result of this research process.

To evaluate the model designed by LISREL program, $\chi^{2}$ index, root mean square residual (RMR), goodness of fitness index (GFI), adjusted goodness of fit index (AGFI), normed fit index (NFI), non-normed fit index (NNFI), increasing the fitness index (IFI), comparative fit index (CFI), and root mean square error of approximation (RMSEA) were used. GFI and AGFI values reported for these two models were both higher than 0.9 and the value of RMR in this study was $(0.0043)$ which demonstrates an appropriate explanation of covariance and a negligible value of RMSEA which was (0.007). This negligible value of this index (0.007) for the designed model in this study indicates a very appropriate fit of the collected data and their excellent FIT.

\section{Discussion and conclusion}

The aim of this study was to explore the relationship between OCB and staff's organizational commitment in Physical Education Departments in Iran. Citizens as a 
people who formed human societies were not regarded by leaders or managers in recent years but now they are regarded by those who want to have a peculiar role in human lives. In this case, leaders need their citizens' votes for their legislators and businessmen, traders, industrialists, writers, journalists, and all those who are generally present at the scene of all human lives need to pay attention to citizens' mental needs as well as demands. Individual behavior in the workplaces has long been considered by experts of management sciences and the emerging organizational behavior has been considered more in this case. Most of the studies have tried to classify behaviors and their present or emerging reasons. Issues such as perception, motivation, occupational attitudes, and organizational commitment are among the factors that analyze most of human behaviors in workplace. But the issue which has been presented in the recent two decades and also behaviorists, psychologists, and sociologists regarded is called OCB. Organizational commitment reflects people's attitudes toward organizational values and goals and represents a force that requires a person to remain in the organization and its membership and does whatever is necessary for achieving organizational goals.

Organizational commitment caused increase of OCB. Organizational commitment is significantly associated with some aspects of OCB. Individuals committed to organization show more sacrifice, prudence, and loyalty. Findings of this study indicate that there is a significant relationship between OCB and organizational commitment. Besides, results regarding significant relationship between OCBs and staff's organizational commitment are similar to studies by Ensher et al. (2001), Gautam et al. (2005), Haigh and Pfau (2006), Lavelle et al. (2009), Salehi and Gholtash (2011), Zeinabadi and Salehi (2011), and Mirabizadeh and Gheitasi (2012). The main hypothesis of the study results indicates that there is significant relationship between OCB and organizational commitment.

According to Confirmed Relations in this research, it is concluded that increase of OCB improves staff's organizational commitment, which will generally enhance effectiveness and efficiency of the organization's activities. Loyal manpower is willing to remain a member of organization based on the goals and values of the organization and willing to go beyond the required tasks which can be an important factor of effectiveness of the organization. The existence of such forces in organization will increase performance and reduce the absence of the staff, delay, and turnover to increase the level of organizational commitment and shows organization's prestige well in society and cause more growth and development of organization.

By an extensive reviews and a comparison, we conducted relations between OCB and organizational commitment in the Iranian context and educational environment culture. Result of this research showed that it was necessary for organizational commitment within an organization to improve its performance and the organizational commitment was significantly related with OCB. For example, Salehi and Gholtash (2011) in Iran showed that variable of organizational commitment had a positive effect on the OCB. Also, a review of the previous studies such as Meyer and Allen (1990), Ensher et al. (2001), Gautam et al. (2005), Haigh and Pfau (2006), Liu (2009), Lavelle et al. (2009), Ng and Feldman (2011), Morin et al. (2011), Chen and Kao (2012), and Islam et al. (2012) indicates that positive OCB is effective on 
organizational commitment. Therefore, these results show that physical education managers, based on the proposed strategies, should be able to increase rate of staff's organizational commitment. Managers can be helpful by empowering employees; hiring competent individuals, using meritocracy system, creating job security for employees, and sharing employees in the decision-making aid in developing staff's capabilities to achieve functionality and enhance organizational commitment.

Research results of the first sub-hypothesis indicate that there is significant relationship between OCB and affective commitment of employees and increasing the rate of emotional commitment in employees has greater effect on citizenship behavior and improves citizenship behavior that generally enhances effectiveness and efficiency of the organization's activities. So, it is recommended that Iranian physical education managers should specify organization's main goals and values, have effective communication with employees and know employees' values to increase rate of staff's affective commitment, and they should try to make harmony between organization's values and employees should be consistent with each other in a way that employees make themselves responsible for success of organization and improve organization's roles through their voluntarily actions.

Research results of the second sub-hypothesis indicate that there is a significant relationship between OCB and staff's continuance commitment and the ongoing commitment of staff mostly have a greater impact on promotion of citizenship behavior that increases effectiveness of the overall efficiency of the organization's activities. So if an organization employs people whose stay in organization is their main concern and who have commitment toward their organization, it can be an important point for organization and improve organization's efficiency.

Research results of the third sub-hypothesis indicate that there is significant relationship between OCB and employees' normative commitment. Increase in rate of employees' affective commitment will have a greater effect on citizenship behavior that generally enhances effectiveness and efficiency of the organization's activities. In normative commitment, people will remain faithful and committed to organization based on their sense of duty and moral commitment toward organization. It is recommended that Iranian physical education managers make employees fond of organization by investment in occupational instruction period, provide suitable opportunity for staff's families, and hold festivals in the presence of personnel's families in various occasions in a way that employees do their best to make organization reach its goals and consequently do their duties in the best way. Finally, considering that limited researches have been conducted to examine the relationship between OCB and organizational commitment based on Graham's OCB model and Allen and Meyer's OC model in Physical education departments, this study has limitations like other researches. Also, focus of the results is first on the sport setting and further research can be performed in other organizations and industries. Certainly, objectives of the Physical Education Departments are different from those of other organizations and may have results that are different from others. Second, managers must be aware of the staff's perceptions to create a better incentive and positive commitment. Therefore, further researches can be used to measure the employees' perceptions to enhance positive organizational commitment. Third, the leadership style can be effective on the organizational commitment 
and OCB; further researches could measure effect of leadership style, organizational commitment, and OCB simultaneously. Another limitation of this study is related to correlation research. When conducting correlation research, one should consider many issues some of which are negative in nature. A limitation of correlation research is that it does not allow testing strong causal inference. Thus, a bivariate correlation coefficient gives information about the nature of the relations between two variables but not why they are related. Another limitation of correlation methods is that they commonly suggest that the variables are linearly related to one another.

\section{References}

ALotaibi, A. G. (2001). Antecedents of organizational citizenship behavior a study of public personnel in Kuwait. Public Personnel Management, 30(3), 350-363.

Allen, N. J., \& Meyer, J. P. (2000). Construct validation in organizational behavior research: The case of organizational commitment. Problems and Solutions in Human Assessment (pp. 285-314). New York: Springer. doi:10.1007/978-1-4615-4397-8_13.

Batman, T. S., \& Organ, D. W. (1983). Job satisfaction and the good soldier: The relationship between affect and employee "citizenship". Academy of Management Journal, 26, 587-595. doi:10.2307/ 255908.

Bergeron, D. M. (2007). The potential paradox of organizational citizenship behavior: Good citizens at what cost? Academy of Management Review, 32(4), 1078-1095. doi:10.5465/AMR.2007.26585791.

Bienstock, C. C., DeMoranville, C. W., \& Smith, R. K. (2003). Organizational citizenship behavior and service quality. Journal of Services Marketing, 17(4), 357-378. doi:10.1108/08876040310482775.

Bolino, M.C., Turnley, W.H., \& Bloodgood, J. M. (2002). Citizenship behavior and the creation of social capital in organizations. Academy of management Review, 27(4), 505-522. http://www.jstor.org/ stable/4134400.

Chen, C. H. V., \& Kao, R. H. (2012). Work values and service-oriented organizational citizenship behaviors: The mediation of psychological contract and professional commitment: A Case of Students in Taiwan Police College. Social Indicators Research, 107(1), 149-169. doi:10.1007/ s11205-011-9832-7.

Chompookum, D., \& Derr, C. B. (2004). The effects of internal career orientations on organizational citizenship behavior in Thailand. Career Development International, 9(4), 406-423. doi:10.1108/ 13620430410544355.

Cohen, A. (1993). Age and tenure in relation to organizational commitment: A meta-analysis. Basic and Applied Social Psychology, 14(2), 143-159. doi:10.1207/s15324834basp1402_2.

Cohen, A. (2006). The relationship between multiple commitment and organizational citizenship behavior is Arab and Jewish culture. Journal of Vocational Behavior, 69(1), 105-118. doi:10.1016/j. jvb.2005.12.004.

Dickinson, L. (2009). An examination of the factors affecting organizational citizenship behavior. University of Tennessee, Knoxville, TN. p. 43. Available at: http://www.utc.edu/departmentalhonors/pdfs/dickinsonl.pdf.

DiPaola, M., \& Tschannen-Moran, M. (2001). Organizational citizenship behavior in schools and its relationship to school climate. Journal of School Leadership, 11(5), 424-447. Available at: http:// wmpeople.wm.edu/asset/index/mxtsch/_22.

Ensher, E. A., Grant-Vallone, E. J., \& Donaldson, S. I. (2001). Effects of perceived discrimination on job satisfaction, organizational commitment, organizational citizenship behavior, and grievances. Human Resource Development Quarterly, 12(1), 53-72.

Farh, J. L., Early, P. C., \& Lin, S. C. (1997). Impetus for action: A cultural analysis of justice and organizational citizenship behavior in Chinese society. Administrative Science Quarterly, 42, 421-444. 
Garg, P., \& Rastogi, R. (2006). Climate profile and OCBs of teachers in public and private schools of India. International Journal of Educational Management, 20(7), 529-541. doi:10.1108/ 09513540610704636.

Gautam, T., Van Dick, R., \& Wagner, U. (2004). Organizational identification and organizational commitment: Distinct aspects of two related concepts. Asian Journal of Social Psychology, 7(3), 301-315. doi:10.1111/j.1467-839X.2004.00150.x.

Gautam, T., Van Dick, R., Wagner, U., Upadhyay, N., \& Davis, A. J. (2005). Organizational citizenship behavior and organizational commitment in Nepal. Asian Journal of Social Psychology, 8(3), 305-314. doi:10.1111/j.1467-839X.2005.00172.x.

Graham, J. W. (1991). An essay on organizational citizenship behavior. Employee Responsibilities and Rights Journal, 4(4), 249-270. doi:10.1007/BF01385031.

Hackett, R. D., Lapierre, L. M., \& Hausdorf, P. A. (2001). Understanding the links between work commitments constructs. Journal of Vocational Behaviors, 58(3), 392-413. doi:10.1006/jvbe.2000. 1776.

Haigh, M. M., \& Pfau, M. (2006). Bolstering organizational identity, commitment, and citizenship behaviors through the process of inoculation. International Journal of Organizational Analysis, 14(4), 295-316. doi:10.1108/19348830610849718.

Islam, T., Khan, S. R., Shafiq, A., \& Ahmad, U. N. U. (2012). Leadership, citizenship behavior, performance and organizational commitment: The mediating role of organizational politics. World Applied Sciences Journal, 19(11), 1540-1552. doi:10.5829/idosi.wasj.2012.19.11.2093.

Kidwell, R. E., Mossholder, K. W., \& Bennett, N. (1997). Cohesiveness and organizational citizenship behavior: A multilevel analysis using work groups and individuals. Journal of Management, 23(6), 775-793. doi:10.1177/014920639702300605.

Kim, W. G., Leong, J. K., \& Lee, Y-K. (2005). Effect of service orientation on job satisfaction, organizational commitment, and intention of leaving in a casual dining chain restaurant. Hospitality management, 24, 171-193. Available at: http://www.sciencedirect.com/science/article/pii/ S0278431904000489.

Krejcie, R.V., \& Morgan, D. W. (1970). Determining sample size for research activities, Educational and Psychological Measurement, 30(3), 607-610. Available at: http://opa.uprrp.edu/InvInsDocs/ KrejcieandMorgan.pdf.

Lavelle, J. J., Brockner, J., Konovsky, M. A., Price, K. H., Henley, A. B., Taneja, A., et al. (2009). Commitment, procedural fairness, and organizational citizenship behavior: a multifocal analysis. Journal of Organizational Behavior, 30(3), 337-357. doi:10.1002/job.518.

Lepine, J. A., Erez, A., \& Johnson, D. E. (2002). The nature and dimensionality of organizational citizenship behavior: A critical review and meta-analysis. Journal of Applied Psychology, 87(1), 52-65. doi:10.1037/0021-9010.87.1.52.

Liu, Y. (2009). Perceived organizational support and expatriate organizational citizenship behavior: The mediating role of affective commitment towards the parent company. Personnel Review, 38(3), 307-319. doi:10.1108/00483480910943359.

Luthans, F. (2006). Organizational behavior. New York: McGraw-Hil.

Markovits, Y., Ullrich, J., van Dick, R., \& Davis, A. J. (2008). Regulatory foci and organizational commitment. Journal of Vocational Behavior, 73(3), 485-489. doi:10.1016/j.jvb.2008.09.004.ISSN: 0001-8791.

Mathieu, J., \& Zajac, D. (1990). A review of meta-analysis of the antecedents, correlates and consequences of organizational commitment. Psychological Bulletin, 108(2), 171-194.

Meyer, J. P., \& Allen, N. J. (1990). The measurement and antecedents of effective continuance and normative commitment to the organization. Journal of Occupational Psychology, 63(1), 1-18. doi:10.1111/j.2044-8325.1990.tb00506.x.

Meyer, J. P., \& Allen, N. J. (1991). A three-component conceptualization of organizational commitment. Human Resources Management Review, 1(1), 61-89. doi:10.1016/1053-4822(91)90011-Z.

Meyer, J., \& Allen, N. (1997). Commitment in the workplace. Thousand Oaks, CA: SAGE Publications.

Meyer, J. P., Stanley, D. J., Hesrscovich, L., \& Topolnytsky, L. (2002). Affective continuance and normative commitment to the organization: A Meta analysis of antecedents, correlates, and consequences. Journal of Vocational Behavior, 61(1), 20-52. doi:10.1006/jvbe.2001.1842.

Mirabizadeh, M., \& Gheitasi, S. (2012). Examining the organizational citizenship behavior as the outcome of organizational commitment: Case study of universities in Ilam. Management Science Letters, 2(3), 951-960. doi:10.5267/j.ms1.2012.01.016. 
Moorman, R. H., \& Blakely, G. L. (1995). Individualism-collectivism as an individual difference predictor of organizational citizenship behavior. Journal of Organizational Behavior, 16(2), 127-142. doi:10.1002/job.4030160204.

Morin, A. J. S., Vandenberghe, C., Boudrias, J. S., Madore, I., Morizot, J., \& Tremblay, M. (2011). Affective commitment and citizenship behaviors across multiple foci. Journal of Managerial Psychology, 26(8), 716-738. doi:10.1108/02683941111181798.

Morrow, P. C. (1983). Concept redundancy in organizational research: the case of work commitment. Academy of Management Review, 8(3), 486-500. doi:10.5465/AMR.1983.4284606.

Mowday, R. T., Porter, L. W., \& Steers, R. M. (1982). Employee organizational linkages. New York: Academy Press.

Mowday, R.T., Porter, L.W., \& Steers, R.M. (1983). Employee-organization linkages: The psychology of commitment, absenteeism and turnover. American Journal of Sociology, 88(6), 1315-1317. Article Stable URL: http://www.jstor.org/stable/2778990.

Mowday, R. T., Steers, R. M., \& Porter, L. W. (1979). The measurement of organizational commitment. Journal of Vocational Behavior, 14(2), 224-247. doi:10.1016/0001-8791(79)90072-1.

Ng, T. W. H., \& Feldman, D. C. (2011). Affective organizational commitment and citizenship behavior: Linear and nonlinear moderating effects of organizational tenure. Journal of Vocational Behavior, 79(2), 528-537. doi:10.1016/j.jvb.2011.03.006.

Niehoff, B. P., \& Moorman, R. H. (1993). Justice as a mediator of the relationship between methods of monitoring and organizational citizenship behavior. Academy of Management Journal, 36(3), 527-556. doi:10.2307/256591.

Norris-Watts, C., \& Levy, P. E. (2004). The mediating role of affective commitment in the relation of the feedback environment to work outcomes. Journal of vocational behavior, 65(3), 351-365. Available at: http://www.sciencedirect.com/science/article/pii/S0001879103001271.

O'Reilly, C. A., \& Chatman, J. (1986). Organizational commitment and psychological attachment: The effects of compliance, identification and internationalization on pro-social behavior. Journal of Applied Psychology, 71(3), 492-499. doi:10.1037/0021-9010.71.3.492.

Organ, D. W. (1988). Organizational citizenship behavior: The good soldier syndrome. Lexington, MA: Lexington Books.

Organ, D. W. (1990). The subtle significance of job satisfaction. Clinical laboratory. Management Review, 4(1), 94-98.

Organ, D. W., \& Ryan, K. (1995). A meta-analytic review of attitudinal; and dispositional predictors of organizational citizenship behavior. Personnel Psychology, 48(4), 775-802. doi:10.1111/j.17446570.1995.tb01781.x.

Podsakoff, P. M., \& MacKenzie, S. B. (1994). Organizational citizenship behaviors and sales unit effectiveness. Journal of Marketing Research, 3, 351-363.

Podsakoff, P. M., MacKenzie, S. B., Moorman, R. H., \& Fetter, R. (1990). Transformational leader behaviours and their effects on followers' trust in leader, satisfaction, and organizational citizenship behaviours. Leadership Quarterly, 1, 107-142.

Podsakoff, P. M., Mackenzie, S. B., Paine, J. B., \& Bachrach, D. G. (2000). Organizational citizenship behaviors: A critical review of the theoretical and empirical literature and suggestions for future research. Journal of Management, 26(3), 513-563. doi:10.1177/014920630002600307.

Salehi, M., \& Gholtash, A. (2011). The relationship between job satisfaction, job burnout and organizational commitment with the organizational citizenship behavior among members of faculty in the Islamic Azad University - first district branches, in order to provide the appropriate model, Procedia Social and Behavioral Sciences, 15, 306-310. Available at: http://www.sciencedirect.com/ science/article/pii/S1877042811002709.

Stamper, C. L., \& Van Dyne, L. (2001). Work status and organizational citizenship behavior: A field study of restaurant employee. Journal of Organizational Behavior, 22(5), 517-536. doi:10.1002/job. 100.

Tang, T. L. P., Sutarso, T., Davis, G. M. T., Dolinski, D., Ibrahim, A. H. S., \& Wagner, S. L. (2008). To help or not to help? the good samaritan effect and the love of money on helping behavior. Journal of Business Ethics, 82(4), 865-887. doi:10.1007/s10551-007-9598-7.

Van Dyne, L., \& Ang, S. (1998). Organizational citizenship behavior of contingent workers in Singapore. Academy of Management Journal, 41, 692-703.

Van Dyne, L., Graham, J. W., \& Dienesch, R. M. (1994). Organizational citizenship behavior: Construct redefinition, measurement, and validation. Academy of Management Journal, 37, 765-802. 
Van Scotter, J. R. (2000). Relationship of task performance and contextual performance with turnover, job satisfaction, and affective commitment. Human resource Management Review, 10(1), 7-93. doi:10.1016/S1053-4822(99)00040-6.

Van Scotter, J. R., \& Motowidlo, S. J. (1996). Interpersonal facilitation and job dedication as separate facets of contextual performance. Journal of Applied Psychology, 81, 525-531.

Zeinabadi, H. R., \& Salehi, K. (2011). Role of procedural justice, trust, job satisfaction, and organizational commitment in organizational citizenship behavior (OCB) of teachers: Proposing a modified social exchange model, Procedia Social and Behavioral Sciences, 29, 1472-1481. Available at: http://www.sciencedirect.com/science/article/pii/S1877042811028540. 